\section{Baseline mapping and multivariate statistics as a tool to discriminate the sources of contaminants in an urban environment: the Commune of Santiago (Chile) case study.}

STEFANO ALBANESE ${ }^{1}$, ANTONIO ARUTA ${ }^{1}$, LINDA DANIELE $^{2}$, BENEDETTO DE VIVO $^{3}$, ANNAMARIA LIMA ${ }^{1}$, CLAUDIA CANNATELLI ${ }^{4}$ AND JAMIE T BUSCHER ${ }^{4}$

${ }^{1}$ University of Naples Federico II

${ }^{2}$ Universidad de Chile

${ }^{3}$ Pegaso On-Line University (Italy)

${ }^{4}$ University of Alaska Anchorage

Presenting Author: stefano.albanese@unina.it

The metropolitan area of Santiago (known as "Greater Santiago") has a crucial role for the economic, political, and social development of Chile. Within the Greater Santiago, the Commune of Santiago is a local administrative unit located at the center of the capital city.

During spring 2017, 121 topsoil samples were collected from the Commune, with a nominal density of 1 sample per 0.25 sqkm. An $85 \%$ of the samples were collected within residential areas and the rest in parks. Samples were analyzed to determine their content in major and trace elements (53).

Multifractal IDW interpolation method was applied to raw data to generate the geochemical baseline maps of 15 potential toxic elements (PTEs) and the concentration-area (C-A) plot was applied to grids to set maps intervals.

Subsequently, aiming at discriminating sources of PTEs in the soil, a Principal Component Analysis (PCA) was used to explain the correlation structure of the elements and to find out representative associations of elements. Prior to PCA, isometric log-ratio (ilr) transformation was applied to geochemical data; PCA was completed after the ilr data (including loading, scores, and eigenvalues) were back-transformed to the centered log-ratio (clr) space.

Scores relative to the first two components of PCA (accounting for the $52.1 \%$ and $16.1 \%$ of the total explained variance, respectively) were mapped through MIDW and classified through C-A plot, as well.

Baseline maps of PTEs show that the highest concentrations, generally, correspond to sectors of the Commune historically interested by intense motor-vehicle traffic flow. In the case of mercury $(\mathrm{Hg})$, atmospheric fallout of fumes proceeding from a nearby power plant and some crematoria ovens cannot be excluded as potential sources, as well.

Regarding PCA, first component (PC1), featuring $\mathrm{Sn}, \mathrm{Hg}, \mathrm{Pb}$, -(Be, $\mathrm{Tl})$, potentially represents the association of elements generated by typical urban contamination sources against the geochemical features of volcanic soils (less impacted by human activities in green areas). Besides, tecond component (PC2), including $\mathrm{Sb}, \mathrm{Sn}, \mathrm{Cr},-(\mathrm{Hg})$, allowed to potentially differentiate some sources of the anthropogenic contamination (e.g., motorvehicle exhausts against thermoelectric power plant and crematoria ovens emissions) in the study area.

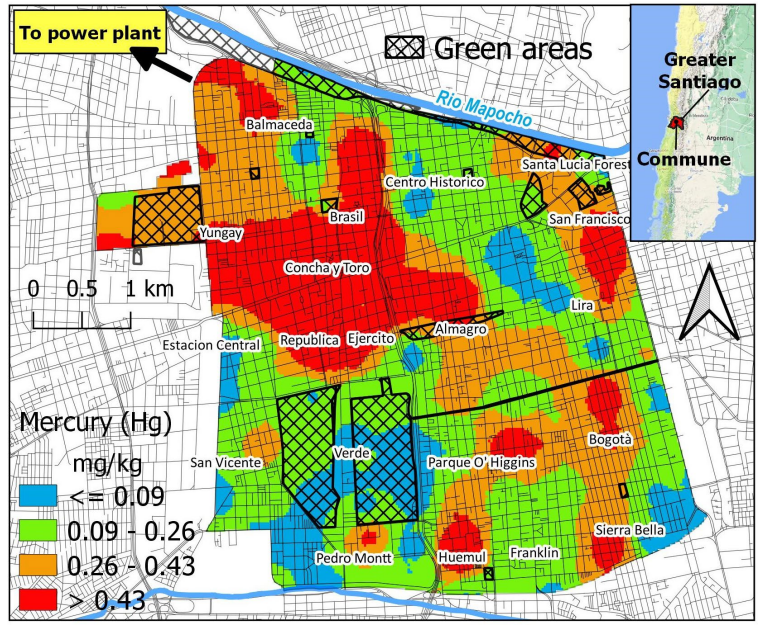

